\title{
Irony, humour and culture in George Mikes' How to Be a Brit: relevance-theoretical perspectives
}

\author{
María Angeles Ruiz-Moneva ${ }^{(0 *}$ \\ Faculty of Philosophy and Letters, University of Zaragoza, 12 Calle de Pedro Cerbuna, 50009 Zaragoza, Spain
}

\section{Article info}

History:

Received August 5, 2019

Accepted September 16, 2019

Published November 7, 2019

Key words:

pragmatics

rhetoric

stylistics

\begin{abstract}
This paper aims to analyse the role played by humour and irony in the interpretation of George Mikes' How to Be a Brit. It will be contended that these resources are important for the reader to understand and enjoy the meaning intended to be communicated by the author. Mikes must have sought to show the inconsistencies and incongruities of the British society and culture, under the perspective of an 'alien', of an outsider. Therefore, irony and humour become stylistic resources that guide the reader's interpretation of the text. The framework applied will be relevance theory, a pragmatic approach which highlights the inferential processes involved in the understanding of a message. However, its views on culture have often been neglected or misunderstood.

This paper will therefore seek to trace whether relevance theory as a whole, and concretely, its proposals concerning humour, irony and culture can help the reader to cope with the meaning of the work under analysis. It will be contended that a proper balance between the reader's inferential derivation of the meaning conveyed by the speaker and his freedom to reach his own conclusions (which are in any case constrained by the text) helps to a better understanding and interpretation of the text.
\end{abstract}

\section{Introduction}

In his work How to Be a Brit ${ }^{1}$, formed by How to Be an Alien, How to Be Inimitable and How to Be Decadent, George Mikes depicts what are reflected as the strange habits of the British as seen by an outsider. How to Be a Brit offers, therefore, highly satiric, humorous and ironic views of the experiences that the author had as a foreigner among the British. Hence, the author's perspective as an alien allows him to reflect and draw on what he regards as his maladjustment to the world knowledge and to the cosmovision of the British.

A certain connection can be established between the work, the protagonist and Mikes, the author himself. In the 'Prefaces' to the works and to the $24^{\text {th }}$ impression, the author refers to his getting in touch with the editor of the first edition of the text, André Deutsch, back in 1945, and the editor's interest in his manuscript. Its central idea was how to be an alien, that is, how to adapt oneself, being a foreigner, to the cosmovision of the British. Reference is made to the reception of the trilogy, which the targets of the author's irony and humour happened to find it 'such a funny book' (Preface, p. 9). This was so even though the author claims that he did not intend to make it humorous, something quite hard to believe:

\footnotetext{
^Email address:mruiz@unizar.es.

${ }^{1}$ George Mikes' How to Be a Brit. A George Mikes Minibus (Penguin, Harmondsworth, 1986) is a compilation of the following three books by the same author: How to Be an Alien (1946), How to Be Inimitable (1960) and How to Be Decadent (1977). In the Preface, the author himself refers to the three of them in the following terms: "How to Be an Alien was a cri de cœur, a desperate cry for help: (...) In due course I added two further shrieks to that first one: How to Be Inimitable in 1960, when we had started to slip but still had an Empire and refused to acknowledge much change; and How to Be Decadent in 1977" (1986, p. 9; italics as in the original). In the paper, references will be made to either How to Be a Brit, or to each single book; in the latter case, in between inverted commas. Single commas (") will be used to quote from concrete fragments.
} 
What is my grievance, then? It is that this book has completely changed the picture I used to cherish of myself. This was to be a book of defiance. Before its publication I felt myself a man who was going to tell the English where to get off. I had spoken my mind regardless of consequences; I thought I was brave and outspoken and expected either to go unnoticed or to face a storm. But no storm came. I expected the English to be up in arms against me but they patted me on the back; I expected the British nation to rise in wrath but all they said, was: 'quite amusing.' It was indeed a bitter disappointment.

(From the 'Preface to the $24^{\text {th }}$ Impression', p. 14)

Mikes was a Hungarian author, born in Budapest in 1912. He held a doctorate in Law. After becoming a journalist, he was sent to London as a correspondent for a short period of time, in the late nineteenththirties, immediately before the Second World War. However, he remained in Britain until his death in 1987. He published both in Hungarian and in English. Some of his other works are also related to several world countries, and living there as a foreigner, such as How to Unite Nations (1963), The Land of the Rising Yen (1970), or Switzerland for Beginners (1978). On his seventieth birthday, he published an autobiography, How to Be Seventy (1982). In a sense, therefore, the situations depicted in the works analysed may have been related to his own vital experience in a foreign country where he was about to live for a long time-span in his lifetime.

Relevance theory (most importantly, Sperber \& Wilson, 1995; Blakemore, 1992; Wilson \& Sperber, 2004; Carston, 2002a; Clark, 2013) offers a coherent account of human communication as an ostensiveinferential process, where the addressee seeks to inferentially recognise the speaker's communicative intention. Misunderstandings may arise as a result of the addressee's wrong identification of the speaker's communicative intention; or also as a mismatch of the cognitive environments of the two, which consequently fails to become 'mutual' or 'mutually manifest'. But at the same time, cultural factors play an essential role in the broadening of the cognitive environment shared by communicator and addressee ${ }^{2}$. All these aspects may be manipulated for the creation of humour and irony, and this is precisely the case with Mikes' How to Be a Brit.

Humour and irony have extensively been covered within the relevance-theoretical framework: the former, in works by authors such as Jodlowiec (1991), Curcó (1995, 1996, 1997a,b, 1998), Torres Sánchez (1999), Yus (1995-1996, 2003, 2004, 2016a), or Biegajło (2014); the latter was addressed even before the theory was explicitly fleshed out (Sperber \& Wilson, 1995), by Sperber \& Wilson (1978, 1981), or Carston $(1980,1981)$ and proposals for its analysis extend up to the present (Yus, 1997-1998, 2000, 2000 2001, 2009, 2012, 2016b, 2016c; Piskorska, 2016; Wilson, 2006, 2009, 2013). The roles played by both irony and humour in the creation of style will be explored. Following the relevance-theoretical framework, it will be assumed that style and stylistic effects guide the addressee's search for optimal relevance.

In How to Be a Brit. A George Mikes Minibus, the author, a Hungarian journalist who arrived in England at the time of the Second World War and who remained there until his death in 1978, tells about his impressions regarding the English people after having been living there for many years. He initially places himself as an outsider to that society, as an 'alien', as he depicts himself, and therefore, introduces a central element of narrative perspective.

Such narrative perspective is essentially characterised by the distance that the speaker establishes between himself and the English. This narrative point of view is also likely to lead to resources such as humour or irony. Even so, he progressively identifies with the British and eventually becomes one of them. As a result, his irony initially adopts the perspective of an outsider, but then his targets are depicted affectionately as well as critically. This is reflected in his "Envoi' which closes "How to Be Decadent": "Let me say one more thing in conclusion. When I wrote that other little book, thirty years ago, I admired the

\footnotetext{
${ }^{2}$ In the paper, culture is understood as the highest or most general level of context. Following Sperber (1996) or Sperber \& Claidière (2008), culture, then, will be seen as a property of human mental representations and practices shared by those individuals that are members of a certain social group or community.
} 
English enormously but did not like them very much; today I admire them much less but love them much more" (p. 263). It seems, therefore, that Mikes' How to Be a Brit may be suitable for the study of what might be called interfaces between irony and humour.

On the whole, Mikes makes fun of some of the most typical habits of the English-what might be called the 'British way of life'. However, he ultimately laughs at what he conceives of as the sense of uniqueness which, in his view, the English seem to feel about themselves.

Irony and humour become central aspects in the interpretation of How to Be a Brit. I shall claim and try to demonstrate that the two resources are closely connected in the work. This is so because on the one hand, the author sets out to mock the British, in particular, what he regards as the British distinctive traits-some of which, nevertheless, are also shared by most of the aliens-; and, on the other hand, he does so by distancing himself from the target of his attacks, and therefore, by being ironic. In the paper, these aspects will be analysed following above all a relevance-theoretical perspective.

\section{Theoretical framework}

The connections between irony and humour have been widely explored throughout history and the discussion comes down to very recent times (Ruiz Gurillo \& Alvarado Ortega, 2013; Attardo, 2001b; Curcó, 1996). For Attardo, "irony may contribute to the perception of humour in a text" (2001b, p. 122). Moreover, both irony and humour may be based on some incongruity or contextual inappropriateness between a certain situation and the expectations raised about it (Attardo, 2000, 2001a). Incongruity has been re-interpreted by Yus $(1995-1996,2003,2004,2016 \mathrm{a})$ in relevance-theoretical terms. There is a clash of possible interpretations, between, on the one hand, the one which is more likely and contextually favoured, and on the other hand, that interpretation which is less likely in relevance theoretical terms, but which is the one ultimately intended to be communicated by the speaker and the one raising humorous effects $^{3}$. The extra processing effort is therefore rewarding for the addressee, and the more so, the grater his responsibility in deriving such an interpretation. Similarly, Curcó (1995) claims that the interpretation of humorous utterances relies upon an interaction between two aspects: namely, the perception and manipulation of the incongruous, and the search for relevance.

Attardo (2001b) points at extra processing efforts in dealing with irony and humour, and therefore opens the way for a relevance-theoretical explanation of both. In fact, within the scope of relevance theory, Curcó (1996) has claimed that both irony and humour are echoic, even though the sources of echo in either are different. Thus, irony entails negative inferences, may be understood as indirect negation and echoes explicitly communicated assumptions. In contrast, humour basically relies upon two or more semantic scripts which mutually oppose replace one another and echoes implicitly expressed communicated assumptions. The most basic, first-level kinds of oppositions between scripts, according to Raskin (1985), are real vs. unreal, normal vs. abnormal and possible vs. impossible.

Some of the most important functions of irony include the following (Rodríguez Rosique, 2013): it may strengthen complicity between participants in communication-in particular, whenever they come to share a context or cognitive environment whose access may be hindered to some other participants-; it may be used in argumentative speech as a strategy for persuasion; or it may intensify a particular aspect of criticism. The latter is probably the most important function fulfilled by irony in Mikes' How to Be a Brit.

Within the General Theory of Verbal Humour (henceforth, GTVH) the cognitive construction of scripts, as internalised and structured areas of information, becomes paramount. The GTVH points at six knowledge resources, hierarchically organised, whose presence or absence in texts will determine whether these are humorous or not. These knowledge resources are script opposition, logical mechanism (which

\footnotetext{
${ }^{3}$ Also within the relevance theoretical framework, Curcó $(1995,1996,1997 \mathrm{a}, \mathrm{b}, 1998)$ refers to these as key assumption and target assumption, respectively, being the latter, therefore, the one which leads to humorous effects.
} 
corresponds to the resolution phase in incongruity-resolution models of humour), situation, target, narrative strategy and language. The cognitive approach to humour put forward by the GTVH makes this theory compatible, in our view, with a relevance-theoretical approach to humour and also to irony.

Attardo (2001a) sets out to generalise the application of these theories to all kinds of texts, regardless of their length, as is the case of humorous narratives, or of genre. The application of the GTVH to humorous texts larger and more complex than the joke presents two different cases, depending on whether they are structurally similar to or different from a joke. The contributions of pragmatics concern, crucially, the importance to approach meaning in context. This also means considering the speaker's communicative intention, and the fact that she deliberately chooses to leave certain aspects implicit. Those may closely be related to humour, whose meaning is ultimately left to the addressee to infer. Inference, implicatures or presuppositions become, thus, part of the common core of the analytic tools of humour.

The basic analysis of humorous texts proposed by Attardo \& Raskin (1991) is maintained, but it is also expanded by incorporating concepts, such as the distinction between punch and jab lines, and those notions accounting for their possible distribution in a text, namely, strands and stacks. This is so because the humorous line of a text may present a much wider complexity than a joke. Those texts may have different jab lines, scattered throughout the text, as in the case of diffuse disjunctors, like register humour and irony.

Mikes' How to Be a Brit may be said to achieve optimal relevance by showing how the British metarepresent themselves, and also how other foreigners or 'aliens' metarepresent the British. As pointed out by Wilson (1999), metarepresentations may be of four main kinds: thoughts about thoughts; thoughts about utterances; utterances about thoughts; and utterances about utterances. This clash of the two kinds of metarepresentations entertained, respectively by the aliens or foreigners and by the British, becomes the basis for the opposition of scripts that creates humour in the work.

Be that as it may, both irony and humour rely on context for their interpretation, and call for inferential processes. The approach followed in the present paper will take into consideration the following assumptions for the analysis. Humour and irony may be used by speakers aiming at optimal relevance ${ }^{4}$ and represent creative uses of language. In this sense, humour and irony may play an important role in the creation of style in a text. Within relevance theory, it has been assumed that style guides or constrains the addressee's search for relevance (Sperber \& Wilson, 1995; Furlong, 1996; Pilkington, 2000; Wilson, 2011; Clark, 2013, to name but a few representative authors). As for the relationship between irony and humour in the work, our central claim will be that in Mikes' How to Be a Brit the ironic attitude of distance adopted by the narrator reinforces the comic effects intended to be communicated.

Within relevance theory, humour has been addressed by authors such as Jodlowiec (1991), Curcó (1995, 1996, 1997a,b, 1998), Yus (2003, 2016a). On the whole, the main points of relevance theory in connection with the interpretation of humorous utterances may be said to be the following. In principle, these utterances neither depart from any supposed 'literalness' nor need any special processing mechanism. In coping with humorous and also ironic utterances, addressees are supposed to abide by the relevanceguided comprehension heuristic, derived from the presumption of optimal relevance (Wilson \& Sperber, 2004), and which is worded as follows:

RELEVANCE-GUIDED COMPREHENSION HEURISTIC

(a) Follow a path of least effort in driving cognitive effects: test interpretations (e.g. disambiguations, reference resolutions, implicatures, etc.) in order of accessibility.

(b) Stop when your expectations of relevance are satisfied.

(Clark, 2013, p. 119)

This means that any extra processing effort that may be required by certain utterances such as irony or

\footnotetext{
${ }^{4}$ Optimal relevance occurs whenever an utterance or any other stimulus has, on any given interpretation, on the one hand, enough contextual or cognitive effects to be worth the addressee's attention, and also, on the other hand, it puts her to no gratuitous processing effort in achieving such effects.
} 
humour will be surpassed by those contextual and cognitive effects attained by the addressee. Moreover, in the case of the interpretation of figurative language the addressee is supposed to have a much greater amount of freedom and responsibility in reaching the interpretation intended to be communicated by the speaker. This is so because, in utterances where humour or irony play a significant part, the implicatures conveyed by the utterance are communicated with lesser degrees of strength, in the form of weak implicatures (Pilkington, 2000; Blakemore, 1992; Sperber \& Wilson, 1995).

More specifically, and in an application of relevance theory to the interpretation of humorous utterances, Curcó (1995) draws a distinction between foreground and background implications, depending on whether they are relevant - and therefore have contextual effects - on their own or not. These two kinds of implications may be manipulated for the sake of the creation of humorous effects. In fact, this is a key aspect to cope with humour and irony in Mikes' How to Be a Brit.

Curcó also dwells upon the similarities in the processing of humour and irony within relevance theory. Thus, both involve the conveyance of a dissociative attitude, which is manifested by the addressee's need to entertain two contradictory propositions. The clash between conflicting propositions which are presented to the audience with different degrees of focalisation-i.e., background vs. foreground assumptionsand the implications of this for humorous utterances, are aspects thoroughly worked upon and further elaborated by Yus (most notably, 1995-1996, 2003, 2004, 2013, 2016a,b,c).

For Yus, and within the general relevance theoretical framework, the principle of relevance enables addressees to test assumptions in order of accessibility, and also to select the interpretation intended to be communicated by the speaker. This principle is valid and applicable for any form of ostensive-inferential communication. A further and key implication is that resources such as humour or irony do not require any special processing mechanism.

Moreover, Yus $(2003,2012,2016 a)$ deals with the relevance-theoretical account of humour in depth. In humorous utterances, the speaker, that is the humourist, may manipulate the expectations of relevance entertained by the addressee. Thus, the first interpretation congruent with the principle of relevance may initially shortcut the humorous interpretation. No matter if the addressee may be requested to invest further processing efforts, his eventually reaching the humorous intended interpretation, which had initially remained background, will produce additional contextual and cognitive effects. Moreover, the addressee will have selected the humorous interpretation on the sole grounds of his own interpretive process, which is likely to arouse further satisfaction because the cognitive effects outweigh the efforts.

Another principle of the general relevance theoretical account which is applied to the processing of humour has to do with the fact that context is taken to be a cognitive entity which is coped with and chosen by the addressee depending on the accessibility that he enjoys to this context envisaged by the speaker. As Yus notes, "What is inevitable (...) is a readjustment of the addressee's relevance-seeking extensions of context and of his expectations of relevance (mental effort versus cognitive interest) when humorous strategies are detected" (2003, p. 1300). Furthermore, an important aspect introduced by Yus (2003) concerns the fact that the addressee has to be in the mood to be entertained or amused: "Humorous effects such as the enjoyment in the resolution of incongruity are worth this extra cognitive effort, especially if the hearer is ready to join in the joking game" (2003, p. 1300).

What is more, Yus argues that the different phases of the twofold relevance theoretical interpretive process of decoding and inference may be exploited for humorous purposes (2003, p. $1304 \mathrm{ff}$.). This is so mainly because resources such as irony or humour do not require any special processing mechanisms. These phases are the following: extraction of a logical form; ambiguity resolution; reference assignment; enrichment (or filling of a semantic gap, which can be exploited humorously); or the derivation of implicatures. This will be applied to the analysis of humour in Mikes' How to Be a Brit.

Yus (2009; 1995-1996, p. 505) refers to the saturation of information and of cognitive clues as the main aspects shared by the processing of both irony and humour. In the case of irony, there is a criterion of incompatibility among those different contextual sources which allow the addressee to infer the speaker's ironically intended interpretation. On processing a humorous or an ironic utterance, the addressee does 
not follow any peculiar path. The information obtained from the speaker's utterance is processed in a certain context or cognitive environment and will yield cognitive effects. The speaker's utterance may, however, include certain implicatures which are conveyed with various degrees of strength. As this author notes, irony may be closely associated with humour. Moreover, the combination of the two, irony and humour, may reinforce certain existing bonds between communicators, such as friendship, comradeship or even solidarity (Gibbs, 2005; Gibbs \& Colston, 2002).

In the following sections, I will try to demonstrate that in Mikes' How to Be a Brit irony is one more resource at the disposal of humour: it basically sets the context and reinforces the contextual effects to be communicated. In the work, humour allows the writer to point at and satirise the customs, habits, attitudes, characteristics, feelings, etc., of the British; it is connected, therefore, with the author's communicative intention. If this is so, it is mainly because, as relevance theory claims, both irony and humour are echoic, so that the speaker tends to express her attitude-usually of scorn, distance, criticism, or the like-towards her utterance or towards a certain state of affairs. Within a relevance-theoretical perspective, in both irony and humour there are certain incongruities or incompatibilities between the contextual sources accessed by the speaker. Consequently, the addressee will be requested to trace the interpretation that finds most suitable. The more autonomy and responsibility in the derivation of the implicatures communicated through these contextual incompatibilities or incongruities is likely to arouse the more satisfaction in the addressee. Moreover, in Mikes' How to Be a Brit the relationship established between participants - on the one hand, the speaker; on the other hand, the British—may be said to be characterised by its ambivalence and shifting throughout time.

\section{Analysis: strategies and purposes for the conveyance of irony and humour}

Generally, irony and humour may result in misunderstandings if the addressee fails to grasp the speaker's communicative intention, or, to put it otherwise, if he fails to access the cognitive environment pointed at by the speaker. However, in Mikes' How to Be a Brit it is misunderstandings that lead to irony (because of the speaker's attitude of distance towards what he is narrating) and to humour (on account of the situations created, which are often absurd).

The point is, therefore, to analyse the exploitation of humour and irony in the work, and shed light upon the kinds of humorous strategies used by Mikes to convey his puzzled attitude of ironic distance towards what he perceives or interprets as misunderstandings. These are often intercultural grounded. It will be assumed that culture, and also intercultural differences, are a part of the context or cognitive environment. Therefore, any lack of accessibility by either speaker to the context envisaged by her interlocutor is likely to result in misunderstandings.

In the book, both irony and humour become essential devices for the creation of style. In this sense, I will try to show that in Mikes' How to Be a Brit irony and humour tend to complement and counterbalance each other. In it, Mikes tends to laugh at certain aspects of the British, as seen by an outsider who, nevertheless, progressively integrates himself with that society and at least to some extent comes to feel certain sympathy with its members.

Next it will be shown how there are several ways in which Mikes' How to Be a Brit can be said to be echoic. The analysis will focus on the following aspects: to begin with, the 'Prefaces' will be studied, in so far as they show the speaker's attitude, which underlies the expression of irony and of humour in the work. This will be followed by the analysis of humorous strategies employed in the work and the ways in which these are affected by the attitudes of ironic distance adopted by the speaker. Finally, the conclusions of the study will be presented.

\subsection{The Prefaces}

How to Be a Brit is formed by three different parts. The author himself refers to his intentions in writing the book, in the 'Preface' and also in the 'Preface to the $24^{\text {th }}$ impression'. These pieces, therefore, become essential to analyse the author's perspective or standpoint to what he is narrating in the different parts. 
The first of them is "How to Be an Alien" (Mikes, 1946), which, in contrast to the expectations and reactions of its readership, the author claims not to have been intended to be funny or humorous. It is structured into two different sections, 'How to Be a General Alien' and 'How to Be a Particular Alien'. As the author notes, it is meant to show his impressions regarding his living among what he regarded as "strange people" ('Preface', p. 9). This preface also offers instances of humour based on contradictions and on consequences which do not logically follow from the premises or assumptions entertained. Therefore, they involve crucial aspects of incongruity and refer to scripts which contradict each other, since mutually excluding propositions result in the same outcome: "Study these rules, and imitate the English. There can only be one result: if you don't succeed in imitating them you become ridiculous; if you do, you become even more ridiculous" ("How to Be an Alien”, 'Preface', p. 18).

Significantly enough, in his references in the 'Preface' to "How to Be Inimitable: Coming of Age in England" (Mikes, 1960), he shifts and alternates between they and we as the grammatical subject of the clause where he explains the purpose of this part: "In these past twenty-one years England has gained me and lost an Empire" (p. 97; my italics); "After the war it seemed that we would hardly survive the blow of victory; nonetheless today we are nearly as well off as the Germans themselves" (p. 98-99; my italics). $\mathrm{He}$ also addresses his readership directly: "Oh, yes, if you want to be a modern Briton-a Briton of the sixties-you have to follow an entirely a new set of rules. Here they follow" (p. 99; my italics).

A peculiar aspect about Mikes' How to Be a Brit in connection with the target audience has to do with the fact that, in contrast to what was indicated in classical treatises-such as Muecke $(1969,1970,1982)$ or Booth (1974) - there is no clear dichotomy between those who can cope with irony, on the one hand, and those who fail to do so, on the other hand. This is an important feature of irony which in relevance theoretical terms has been accounted for in terms of context accessibility - by authors such as Yus (19971998, 2000,-, 2009, 2012). However, what appears to be the case with the audience or potential target of irony in George Mikes' How to Be a Brit is that it may be regarded as transversal, in the sense that both the British and other kinds of readership may have access to the meaning intended by the speaker. In a sense, this may be due to the blending of humour and irony in the work.

On the whole, the 'Prefaces' set the context and provide the basis for the scripts oppositions leading to humour that will be projected in the rest of each of the three parts of Mikes' How to Be a Brit. They also offer clear indices of the attitude of the speaker and of his communicative intention to distance himself from what he is narrating and from the targets of humour and irony in the work.

\subsection{A relevance-theoretical analysis of humour and irony in $\mathbf{H o w}$ to Be a Brit}

A particularly interesting aspect of Mikes' How to Be a Brit in the analysis of irony and humour concerns the ways in which the same topic is addressed all through the different parts that make it up (namely, "How to Be an Alien", "How to Be Inimitable" and "How to Be Decadent"). This may result in echoic irony and in humour, by showing how the author reacts towards this topic in the earliest pieces of the other books. As for irony, those may be regarded as instances of what Hatim (1997) termed as intertextual echoes, whose source refers to other works or texts and which, in my view, do not only apply to translation. In this sense, a further refinement or distinction between intertextual sources and intertextual echoes can be proposed. The difference between the two lies in that intertextual sources have to do with connections that may be found between different texts, but which, in contrast to intertextual echoes, need not be linked to the conveyance of irony. These intertextual sources may be related to some extent to a manifestation of the principle of confirmation (or reinforcement) of assumptions. In relevance-theoretical terms, this is a cognitive process whereby new information strengthens and provides evidence for old assumptions. In a sense, Hatim's concept of intertextual echoes (1997) would be a specific kind of intertextual sources. Intertextual echoes refer to those manifestations of irony whose source is traced in other different texts. The two parts which follow "How to Be an Alien" also allow the reader to become acquainted with the ways how the book was received, no matter if the author's attitude is clearly humorous and ironic.

Thus, in the different parts of the work these intertextual sources and echoes have to do with such 
aspects of British life as queuing, (not) being clever, views on language, tea, or on shopping. These are the instances on which the analysis will be based.

To begin with, this is what the author remarks about queuing in both "How to Be an Alien" and "How to Be Decadent":

(1) An Englishman, even if he is alone, forms an orderly queue of one.

("How to Be an Alien": 'The National Passion', p. 54)

Quite a few people told me that I was mistaken when I made fun of the English queuing habit. It was simply a war-time expediency, it was explained to me, and it would disappear in no time. It is still with us and will remain with us forever because it corresponds to an inner need, it is a way of self-expression. Other nations need occasional outbursts of madness and violence; the English need occasional excesses of self-discipline. Other nations, under unbearable stress, shout, howl, get into brawls, run amok; the English queue up for a cup of tea.

Demonstrations in other countries are violent affairs, with baton charges and mass arrests. Such things have occurred here, too, in the past. Today, if you are bored, you arrange a demo.

("How to Be Decadent": 'On the National Passion', p. 223)

These are instances which show that irony and humour in How to Be a Brit rely on exaggerations and hyperboles which take everyday actions and customs to the utmost and absurd consequences. In my view, this is where the incongruity rests upon, because of the absurdity of the script oppositions presented. There is also an element of cultural background which underlies this one and many of the humorous situations presented in the work: thus, many of the aspects that are presented as idiosyncratically English are in fact also common, trivial and recurrent in many parts of the world. The assumptions that were presented to be likely to be abandoned are however strengthened and reinforced. What is more, the consequences are taken to the extreme of absurd, unlikely situations. These are presented in what relevance-theory has referred to as ad-hoc concepts ${ }^{5}$ and which Yus $(2004,2016 \mathrm{a})$ has applied to the account of humour. This would hold here in the connection between being bored and arranging a demo, which in usual contexts would bear no resemblance or logical connection whatsoever.

The author's views on how (not) to be clever may be said to stand for instances of echoic irony and humour appearing in two different parts of How to Be a Brit, namely, "How to Be an Alien" and "How to Be Inimitable". In this case, the author holds similar views, so that irony is based on confirmation, or on addressing the same kind of target, with basically the same kind of attitude. Therefore, irony would not be based on intertextual echoes, but rather on intertextual sources. The recurrence is based on the target of irony and on the speaker's attitude towards it. Thus, irony and humour rely on similar views and attitudes:

(2) In England it is bad manners to be clever, to assert something confidently. It may be your own personal view that two and two make four, but you must not state it in a self-assured way, because this is a democratic country and others may be of a different opinion.

(“How to Be an Alien”: 'How Not to Be Clever', p. 42)

One thing you must learn in England is that you must never really learn anything. You may hold opinions - as long as you are not too dogmatic about them—but it is just bad form to know

\footnotetext{
${ }^{5}$ Within relevance-theory, ad hoc concepts are regarded as constituents of the explicature of the speaker's utterance, and give access to the set of encyclopaedic assumptions that enable the derivation of implicatures. The important point is that the properties associated with the ad hoc concept could have been retrieved neither from the concept originally encoded nor from the vehicle alone; rather, they spring from the association of the two (Carston, 2002b). As noted by Clark (2013, p. 249), concepts are always adjusted and specified when they are accessed in a certain context, so that they allow addressees to derive certain implicatures.
} 
something. You may think that two and two make four; you may rather 'suspect it'; but you must not go further than that. Yes and no are about the two rudest words in the language.

(“How to Be Inimitable”: 'On Not Knowing Anything', p. 163; my italics)

In the case of the fragment taken from "How to Be an Alien", humour starts with the punchline of a satiric utterance that contradicts common sense and world knowledge, which may be the conclusion ad absurdum of particular aspects that the author has observed about the British. Humour and also irony are likewise grounded on the attitude of echoic distance adopted by the speaker towards the facts that he interpretsrather than just presenting them-about these group of people. In a sense, he is conveying what are but his opinions as if they were facts or factual assumptions. The reasons provided by the author cannot be said to spring logically from the premises or assumptions. The incongruity also focuses upon the contrast between facts and opinions.

This contrast between facts and opinions, or rather, between knowledge or cognition and opinions, is the aspect that is retaken in "How to Be Inimitable": as in the previous case, there is an absurd statement which is presented as if it were logical and commonsensical enough. Most importantly, the expression of attitude that yields humorous and also ironic effects is grounded on what relevance-theory terms as higher-level explicatures. These involve "embedding the proposition expressed in a higher-level description" (Carston \& Uchida, 1998, p. 297), which may convey, refer to or describe, amongst other aspects, the speaker's propositional attitude. Therefore, they are relevant by guiding and constraining the reader's decisions to be made on the interpretation (Clark, 2013; Blakemore, 1992).

As noted above, the author's perceptions about the attitudes of the British on aspects such as language, or on shopping, for instance, are also recurrent in some or in all three works of How to Be a Brit. Thus, as regards language, in "How to Be an Alien", the author dwells on his impressions on English vocabulary, or on the variety of accents used by native speakers and their social connotations:

(3) If you live here long enough you will find out to your greatest amazement that the adjective nice is not the only adjective the language possesses, in spite of the fact that in the first three years you do not need to learn or use any other adjectives. You can say that the weather is nice, a restaurant is nice, Mr Soandso is nice, Mrs Soandso's clothes are nice, you had a nice time, and all this will be very nice.

(“How to Be an Alien”: 'The Language', p. 37; my italics)

The author is clearly mocking the overuse of the word 'nice' by English native speakers, despite its wide application to the utmost heterogeneous aspects and its little meaning in the end. However, as native speakers use it so often, foreigners will be advised to employ it as well. Mikes also runs into remarkable absurdities of behaviour, which are exploited and stretched to situations which are unlikely to occur in real life. For example, he discusses the social connotations attached to the different accents that may be used by native speakers of English, and results in quite an absurd, albeit very funny situation:

(4) Anyway, this whole language business is not at all easy. After spending eight years in this country, the other day I was told by a very kind lady: 'But why do you complain? You really speak a most excellent accent without the slightest English'.

("How to Be an Alien": 'The Language', p. 41)

In "How to Be Inimitable" the author retakes the issue of the different accents that can be used by people speaking English, and this time he dwells on his own experience, regarding his knowledge of English either before or after coming to England:

(5) When I was set to England in 1938, I thought I knew English fairly well. In Budapest my English proved quite sufficient. I could get along with it. On arrival in this country, I found that 
Budapest English was quite different from London English. I should not like to seem biased, but Ifound Budapest English much better in many ways.

(“How to Be Inimitable”: 'On Not Knowing English', p. 158; my italics)

As this quotation illustrates, one of the main sources of humour in the work has to do with the unexpected conclusions that the author derives. Therefore, he brings a punch line of the joke or humorous text. The topic of language is also found in the third part of the trilogy, namely, "How to Be Decadent":

(6) If you want to sound truly English, you must learn to speak the language really badly. It will not be difficult, there are many language schools where they teach you exactly that. (If you are unlucky you may choose one of the old-fashioned ones and be taught English as it should be, and not as it is, spoken.) Remember that everything is a 'situation' or a 'problem' nowadays. In the old days a man was travelling, today he is in a travel situation.

(“How to Be Decadent": 'Language', p. 197-198)

Thus, the author establishes a distance between his latest works and the previous ones, and also between the attitudes towards the language in the two historical moments concerned. It is quite unexpected and humorous, on the one hand, to hear one who seems to give advice on how to speak a language well, while on the other hand his remarks are quite incongruous and contradictory: can one be sounding truly English ... but speaking the language badly? The author also makes fun of the overuse of shell-nouns, such as thing, problem, or situation, generic terms which are too broad and under-denotative, and yet are used too often by native speakers.

The author's approach to what he regards as the British national passion (that is, queueing) is found both in "How to Be an Alien" and in "How to Be Decadent":

(7) Queueing is the national passion of an otherwise dispassionate race. The English are rather shy about it, and deny that they adore it.

On the Continent, if people are waiting at a bus-stop they loiter around in a seemingly vague fashion. When the bus arrives they make a dash for it; most of them leave by the bus and a lucky minority is taken away by an elegant black ambulance car. An Englishman, even if he is alone, forms an orderly queue of one.

("How to Be an Alien": 'The National Passion', p. 54)

(8) Quite a few people told me that I was mistaken when I made fun of the English queueing habit. It was simply a war-time expediency, it was explained to me, and it would disappear in no time. It is still with us and will remain with us for ever because it corresponds to an inner need, it is a way of self-expression. Other nations need occasional outbursts of madness and violence; the English need occasional excesses of self-discipline. Other nations, under unbearable stress, shout howl, get into brawls, run amok; the English queue for a cup of tea.

(“How to Be Decadent”: 'On the National Passion', p. 223)

Thus, in the two books referred to, queueing emerges as if it were a genuinely British or English habit, and it were not to be found elsewhere. Therefore, a recurrent trait of the two passages is that they both refer to a hypothetical state of affairs which is contradicted by everybody's common experience almost everywhere. The text therefore distances and echoes real-life: queuing actually has to be made by anybody everywhere in many situations in common, everyday life. The author takes this situation to its utmost, absurd or incongruous consequences, and results humorous, in the passage taken from "How to $\mathrm{Be}$ an Alien": "An Englishman, even if he is alone, forms an orderly queue of one".

The exaggerated, hyperbolic perspective is retaken in "How to Be Decadent". The explanation provided is somehow absurd and incongruous: why should queuing be associated with 'a war-time expediency' at 
all? On the other hand, both queuing and the rest of actions referred to by the author, namely, shouting howl, getting into brawls, running amok, are probably undertaken by everyone everywhere (thus, not only by British people alone) under similar circumstances.

In turn, shopping, for instance, can be traced in two other books of How to Be a Brit, namely, both in "How to Be Inimitable" and in "How to Be Decadent":

(9) My greatest difficulty in turning myself into a true Britisher was the Art of Shopping. In my silly and primitive Continental way, I believed that the aim of shopping was to buy things; to buy things, moreover, you needed or fancied. Today I know that $(a)$ shopping is a social-as opposed to a commercial-activity and $(b)$ its aim is to help the shopkeeper to get rid of all that junk.

("How to Be Inimitable": 'On Shopping', p. 124; italics as in the original)

(10) Few British people go shopping because they need something, still less because they can afford it. Shopping is a social occasion-an opportunity for a chat, an opportunity to display your charm, to show the world that you are on Christian-name terms with the butcher's second-assistant and not just a casual who has dropped in from the street. When your turn comes, the butcher's full attention will be yours.

(“How to Be Decadent”: 'Shopping', p. 210)

Once more, the main underlying source of humour and irony has to do with what the author presents as a genuine contrast between continental and British habits, respectively, but which in any case can be found elsewhere. This is reinforced with the use of adjectives: 'silly and primitive Continental way', in "How to Be Inimitable". In "How to Be Decadent" this aspect is particularly reflected through the reference to the different speech acts and social conventions that the act of shopping may be specified: "an opportunity for a chat, an opportunity to display your charm, to show the world that you are on Christian-name terms with the butcher's second-assistant and not just a casual who has dropped in from the street". Moreover, hardly can anybody agree with purchasing is an exclusively social activity, as the author seems to claim in the two passages, even though shopping has indeed a social component, albeit not the main one.

As noted above, one of the ways in which humour may be conveyed and accounted for (Yus, 2003, 2016a) has to do with the exploitation for humorous purposes of the different phases involved in the coding/decoding and inferential aspects of verbal communication. Such phases are the following: extraction of a logical form; ambiguity resolution; reference assignment; enrichment (or filling of a semantic gap, which can be exploited humorously); or the derivation of implicatures. Next, these will be explained and instances of each in the different parts of the How to Be a Brit will be analysed.

\subsubsection{Extraction of a logical form}

A logical form refers to the logical properties of a conceptual representation. It can be either propositional or non-propositional. If propositional or semantically complete, it can be either true or false. If nonpropositional, logical forms correspond to assumption schemas. Thanks to the process of the development or extraction of a logical form, these can be completed into full-fledged assumptions, based on the contextual evidence available.

(11) If you want to be really and truly British, you must become a hypocrite.

(...)

I had a drink with an English friend of mine in a pub. We were sitting on the high chairs in front of the counter when a flying bomb exploded about a hundred yards away. I was truly and honestly frightened, and when a few seconds later I looked 'around, I could not see my friend anywhere. At last I noticed that he was lying on the floor, flat as a pancake. When be realized that nothing particular had happened in the pub he got up a little embarrassed, flicked the dust off his suit, and turned to me with a superior and sarcastic smile. 
'Good Heavens! Were you so frightened that you couldn't move?'

("How to Be an Alien": 'How to Be a Hypocrite', p. 51; my italics)

In the example, an absurd conclusion is being reached by the person who claims not to have been frightened, and has been so up to a degree that he has decided to conceal himself. While the narrator recognises that he was indeed afraid, his friend (who was probably just as scared as he was) pretends not to have been so, and echoes his own feelings and attitude. The ironic and humorous interpretation is strengthened by the fact that the whole scene is narrated from the perspective of the speaker, who does not prevent himself from providing his own interpretation or from mocking his friend's behaviour. Verbally, it is expressed through the derivation of possible consequences of the fact of being afraid. Here, in the communicative interchange between the author and his friend, the proposition is enriched with the derivation of implicated conclusions: "Were you so frightened that you couldn't move?".

\subsubsection{Resolution of ambiguities or disambiguation}

Ambiguity resolution or disambiguation is another of the inferential steps to be taken by the addressee when coping with the meaning intended to be communicated by the speaker. It has to do with both the recovery of the explicatures of an utterance and with the selection of the propositional form intended to be communicated by the speaker. Within relevance theory, it is shown that this is a process guided by the expectations of relevance entertained by the addressee, on the basis of his access to the contextual evidence available. In Mikes' How to Be a Brit this can be illustrated in passages such as the following:

(12) It is so much nicer to ask, when someone speaks of Barbados, Banska Bystrica or Fiji: 'Oh those little islands ... Are they British?'

(They usually are).

(“How to Be an Alien”: 'How Not to Be Clever', p. 44)

The text shows the speaker making fun of the British cosmovision. Humour is reinforced through the final understatement, which makes it clear which is the speaker's point of view, and also her interlocutor's attitude. Either a positive or a negative answer might have been possible, and therefore, the addressee is requested to entertain two possible scenarios. In the context, it is only the positive answer that enhances and reinforces certain stereotypical assumptions generally entertained about the British. In the end, it is this one that is recovered in the context and that gives way to humorous effects. The question put forward is ultimately rhetorical, since a positive answer was expected (at least from the point of view of the British, in accordance with the author's assumptions). The possible ambiguity concerning whether "those little islands" were British or not is therefore disentangled and spelled out.

\subsubsection{Reference assignment}

Within relevance theory, reference assignment is one of the subtasks involved in the identification of a propositional form. Its function is to make it possible that pronouns and other deictic expressions are related to the conceptual entity they refer to.

(13) Bargaining is a repulsive habit; compromise is one of the highest human virtues - the difference between the two being that the first is practised on the Continent; the latter in Great Britain.

(“How to Be an Alien”: 'How to Compromise', p. 48; my italics)

As is well known, the contrast between Britain and the rest of the European Continent is the major theme of Mikes' How to Be a Brit. No matter if the underlying message seems to be that what is being criticised about the British can so be done about anybody else, the presumed differences between the British and the rest of the world are enhanced. These contrasts are exaggerated and often give way to humour and irony. It becomes, therefore, very important to determine which is the referent in each case. 
The point is here to make it clear what the following terms refer to: namely, the two (which refers to bargaining and to compromise), the first (referring to bargaining) and the latter (associated with compromise). Moreover, this is exploited for humorous and also for ironic purposes, since it is quite unclear that there may be any difference between the two, despite the contrasts claimed to exist between them, on the one hand, and between Britain and the rest of Europe, on the other hand.

\subsubsection{Enrichment or filling of a semantic gap}

In natural language, utterances often tend to be semantically incomplete. Depending on the context envisaged by the speaker, and most importantly, the context accessed by the addressee, the latter will tend to enrich the logical form of the utterance and reduce its indeterminacies. This is so done in the process of searching for a relevant interpretation of the utterance, so that it produces optimal contextual effects without demanding too large processing efforts. As noted by Clark (2013, p. 179), with a view to satisfying expectations of relevance, the addressee may set out to flesh out the explicit content of an utterance even beyond the level of the full proposition which can be either true or false:

(14) I heard of a distinguished, pure-minded English publisher who adapted John Steinbeck's novel The Grapes of Wrath, so skilfully that it became a charming little family book on grapes and other fruits, with many illustrations.

(“How to Be an Alien”: 'A Word on Some Publishers', p. 36; my italics)

The process of enrichment may lead to the creation or entertainment of assumptions which may have been unexpected, and the result may be eventually humorous. This can be the case of what happens in the example above, where the title of the book by Steinbeck has been further developed wittily to criticise the editorial tasks performed by some publishers. This aspect is moreover the main target of criticism developed by the author in ironic and satirical terms.

\subsubsection{Derivation of implicatures}

In relevance-theoretical terms, implicatures are defined as assumptions ostensively communicated which are derived exclusively through processes of pragmatic inference. Implications are conclusions that can logically be extracted from certain premises or assumptions. In turn, implicatures are intentionally communicated implications (Clark, 2013, p. 216). There are two basic types of implicatures, namely, implicated premises and implicated conclusions. In relevance theory, it is considered that the addressee must reach and derive such implicatures so as to infer the meaning intended by the speaker. These may be exploited for humorous effects, so that absurd or at least unexpected conclusions may be derived from the evidence provided. Let us illustrate how this works in Mikes' How to Be a Brit:

(15) Q: Why don't they [the British] work harder?

A: They just don't like hard work. The Germans have a reputation for hard work, so they like to keep it up. The British find it boring. Then, apart from a tiny and despicable minority, the British dislike the idea of taking part in the rat race. They will give up certain advantages-knowingly and with their eyes open - in order to be able to stick to certain values and a way of life.

(“How to Be Decadent”: 'How to Panic Quietly', p. 237)

The passage above is inserted in a chapter or section of "How to Be Decadent" devoted to studies that were undertaken by foreign media which, according to Mikes, sought to identify the reasons for what he terms as 'the English disease', namely, the lack of any worries, concern or even despair or panic on the part of the British after the loss of the Empire (and which contradicted the expectations of those foreign newspapers or magazines). In it, therefore, ' $Q$ ' refers to the interviewer, who is a journalist working in any these foreign media, and 'A' would reflect the perspective of Mikes or the protagonist of How to Be a Brit.

In this fragment, the speaker (that is, Mikes or the protagonist) follows a reasoning process in which the encyclopaedic entries conventionally attached to the British and the German ways of life, respectively, are presented. While it might have seemed that it was the German style the one supposed to be appraised, the British are shown to be reluctant to abandon their customs and habits. 


\subsubsection{Irony and humour resulting from a contradiction of expectations}

Some of the main sources for humour in the work have to do with the perspective or point of view adopted. It is often reflected as a disruption of expectations, which may be expressed in different ways, such as the conditionals whose fulfilment is impossible but which are worded as only improbable or unlikely. Some rhetorical figures also enhance and strengthen the intended interpretation, thus guiding the reader towards it and its relevance.

In relevance-theoretical terms, the disruption of expectations leading to humour is inscribed in the two-stage processing of utterances, following a process of mutual parallel adjustment (Clark, 2013, p. 144) ${ }^{6}$. In the case of humorous utterances, this process of mutual parallel adjustment is explained in the following terms: "If the utterance does not satisfy these expectations, a search for a more relevant (and humour-connoted) interpretation worth being processed may be activated, despite this supplementary mental effort" (Yus, 2004, p. 324)7. This author also explains how humorists tend to manipulate which is the information that is accessible or salient for the audience, so that certain implications of (humorous) utterances may be backgrounded and even irrelevant in certain contexts, but surely not in different ones.

This can be seen in the following example:

(16) The British meteorologists forecast the right weather-as it really should be-and then these impertinent little anti-cyclones interfere and mess up everything.

That again proves that if the British kept to themselves and did not mix with foreign things liked Polar and Azores anti-cyclones they would be much better off.

(“How to Be an Alien”: 'The Weather', p. 29)

Not only does the author mock at the British and the ways in which they perceive themselves, or the ways how others (the foreigners, including the author) regard them. Instances of self-addressed irony or humour may also be traced. They may show the author's (hence, the speaker's) perspective towards what he is narrating, may come in the form of understatements and may show ambiguity, contradiction, or even absurdities. This is so because the conclusions derived cannot be logically derived from the assumptions entertained, which are therefore what Curcó (1997b, 1998) refers to as the key assumptions:

(17) I don't quite know what anti-cyclones are, but this is not important; I hate cyclones and I am very anti-cyclone myself.

(“How to Be an Alien”: 'The Weather', p. 29)

\section{Conclusions}

George Mikes' How to Be a Brit is a work where irony and humour play an essential role in the creation not only of meaning, but also of style. Therefore, they have been found to guide the reader in the search for relevance: thus, the analysis has shown that the different phases followed by him in the interpretive process have been exploited and manipulated for the creation of humour and irony. Moreover, neither humour nor irony represents any substantial or qualitative departure from the interpretation of any utterance.

On the one hand, irony is connected to the speaker's feelings, intention and attitude. This is so because his attitude may be characterised for the remarkable distance that he adopts from the target of his criticism. The protagonist of Mikes' How to Be a Brit depicts himself as an outsider, as an alien, and adopts a perspective of distance - and sometimes of a certain superiority, or more precisely, detachment-from his intended targets of criticism.

\footnotetext{
${ }^{6} \mathrm{~W}$ ithin the relevance-theoretical framework, the process of mutual parallel adjustment accounts for the tasks undertaken by the addressee when trying to understand the message communicated by the speaker. These tasks have to do with the working out of explicatures, of implicated premises and also of implicated conclusions. These processes are worked out in parallel.

${ }^{7}$ Similar claims had previously been put forward by Jodlowiec (1991).
} 
On the other hand, humour can be related to the writer's central purpose of mocking or satirising those aspects of British life that he has found remarkable in some sense. On the whole, irony may be seen as being at the disposal of humour, as a form of reinforcement of the conveyance of the author's communicative purposes. Thus, irony and humour may be seen as complementary and reinforcing each other in the author's creation of style.

The analysis of Mikes' How to Be a Brit, based on the relevance-theoretical approach to communication, shows that irony is essentially echoic. This means that irony has two fundamental traits: first, it implicitly expresses the speaker's attitude to the beliefs, thoughts or ideas being represented; and second, the attitude involved in the echo corresponds to the speaker's dissociation from the thoughts echoed. In the book, this is seen in the standpoint adopted by the protagonist who, being characterised as an 'alien', as a foreigner, amongst a strange people, manages to unmask their contradictions. No matter if his attitude is of distance or dissociation, some of the aspects criticised may be applicable to many other people and even to himself, so that he gradually becomes identified with the object or target of his criticism.

As for humour, it has been shown that in Mikes' How to Be a Brit, it is often based on the contradiction or twist of expectations that lead the reader to revise an initially more accessible interpretation. That interpretation is reached following the inferential procedures which are applicable to any kind of discourse. In this way, the reader tends to select the interpretation that is most accessible in a certain context. Yet, the broadening or extension of such context often tends to favour or foreground an alternative interpretation, which may have been initially undermined or backgrounded and which results in humour. The analysis has shown that, as predicted by Yus (1995-1996, 2003, 2004, 2016a), the same inferential strategies at work in the processing of everyday speech can be applied to the interpretation of humorous discourse.

Recurrent traits in the analysis of irony and humour have also been found, which can be accounted for from a relevance-theoretical perspective. Thus, the analysis of Mikes' How to Be a Brit also provides evidence for the consideration of both irony and humour as echoic uses of language. In the work, the speaker-who may be said to represent the 'real' or 'historical' author Mikes-distances himself from the target of his criticism, and does so by presenting a somehow distant, detached picture of the British, who correspond to his main target.

Irony has been found to be used as one of the vehicles or instruments enabling the author to convey humour as intended to be communicated by the speaker. All in all, the analysis has shown that humour and irony do not demand any specific processing mechanisms or routes. The two can be approached as aspects of style, and as such guide the reader's search for relevance. As a result, their interpretation follows the same interpretive processes as any other utterance. These interpretive processes are then manipulated for the creation of irony and humour. Neither irony nor humour is therefore a property of a certain text. Rather, they represent aspects of the addresser's communicative intention, they are also reflected in the style of the text and as such guide or constrain the addressee's search for relevance and the recovery of the message intended to be communicated. It is ultimately left to the addressee to interpret a piece of discourse as containing irony or humour, or both, and it is precisely the addressee's engagement in the application of his own interpretive mechanisms that will make irony and humour most enjoyable.

\section{Bibliography}

Attardo, S. (2000). Irony as relevant inappropriateness, in "Journal of Pragmatics", 32 (6), p. 793-826, Crossref. Attardo, S. (2001a). Humorous Texts: A Semantic and Pragmatic Analysis, Mouton de Gruyter, Berlin, Crossref.

Attardo, S. (2001b). Humor and Irony in Interaction: From Mode Adoption to Failure of Detection, in Anolli, L., Ciceri, R. \& Riva, G. (eds), Say not Say: New perspectives on miscommunication, IOS Press, Amsterdam, p. 165-185.

Attardo, S. (2013). Intentionality and Irony, in Ruiz Gurillo \& Alvarado Ortega (2013), p. 39-57, Crossref.

Attardo, S. \& Raskin, V. (1991). Script theory revis(it)ed: joke similarity and joke representation model, in "Humor", 4 (3-4), p. 293-347, Crossref.

Biegajło, M. (2014). From which position should I get this joke?! A relevance-driven joke interpretation: Naive optimism, cautious optimism, sophisticated understanding?, in "International Studies in Humour", 3 (1), p. 2-14, [online].

Blakemore, D. (1992). Understanding Utterances: An Introduction to Pragmatics, Blackwell, Oxford. 
Booth, W. (1974). A Rhetoric of Irony, The University of Chicago Press, Chicago / London.

Carston, R. (1980). Approaches to Verbal Irony, MA thesis, University College London.

Carston, R. (1981). Irony and parody and the use-mention distinction, in "Nottingham Linguistic Circular", 10, p. 24-35.

Carston, R. (2002a). Thoughts and Utterances, Blackwell, Oxford, Crossref.

Carston, R. (2002b). Metaphor, ad hoc concepts and word meaning - More questions than answers, in "UCL Working Papers in Linguistics", 14, p. 83-105.

Carston, R. \& Uchida, S. (1998). Relevance Theory. Applications and implications, John Benjamins, Amsterdam / Philadelphia, Crossref.

Clark, B. (2013). Relevance Theory, Cambridge University Press, Cambridge, Crossref.

Curcó, C. (1995). Some observations on the pragmatics of humorous interpretations. A relevance-theoretic approach, in "UCL Working Papers in Linguistics", 7, p. 27-47.

Curcó, C. (1996). The implicit expression of attitudes, mutual manifestness and verbal humour, in "UCL Working Papers in Linguistics", 8, p. 89-99.

Curcó, C. (1997a). The Pragmatics of Humorous Interpretations: A Relevance-Theoretic Account, unpublished PhD dissertation, University College London.

Curcó, C. (1997b). Relevance and the manipulation of the incongruous: Some explorations of verbal humour, in Groefsema, M. (ed.), Proceedings of the University of Hertfordshire Relevance Theory Workshop, Peter Thomas and Associates, Chelmford, p. 68-72.

Curcó, C. (1998). Indirect echoes and verbal humour, in Rouchota, V. \& Jucker, A. H. (eds), Current Issues in Relevance Theory, Benjamins, Amsterdam, p. 304-325, Crossref.

Furlong, A. (1996). Relevance Theory and Literary Interpretation, $\mathrm{PhD}$ thesis, University of London.

Gibbs, R. W. (2005). Irony as persuasive communication, in Colston, H.L. \& Katz, A.N. (eds), Figurative Language Comprehension. Social and Cultural Influences, L.E.A., Mahwah, p. 131-151.

Gibbs, R. W. \& Colston, H.L. (2002). The risks and rewards of ironic communication, in Anolli, L., Ciceri, R. \& Riva, G. (eds), Say not to Say: New Perspectives on Miscommunication, IOS Press, Amsterdam, p. 181-194.

Hatim, B. (1997). Communication across Cultures. Translation Theory and Contrastive Text Linguistics, University of Exeter Press, Exeter.

Jodlowiec, M. (1991). What makes jokes tick, in "UCL Working Papers in Linguistics", 3, p. 241-253.

Mikes, G. (1986). How to Be a Brit. A George Mikes Minibus, Penguin, Harmondsworth.

Muecke, D. C. (1969). The Compass of Irony, Methuen, London.

Muecke, D.C. (1970). Irony, Methuen, London.

Muecke, D. C. (1982). Irony and the Ironic, Methuen, London.

Pilkington, A. (2000). Poetic Effects. A relevance theory perspective, John Benjamins, Amsterdam/ Philadelphia, Crossref.

Piskorska, A. (2016). Echo and inadequacy in ironic utterances, in "Journal of Pragmatics", 101, p. 54-65, Crossref.

Raskin, V. (1985). Semantic Mechanisms of Humor, Reidel, Dordrecht, Crossref.

Rodríguez Rosique, S. (2013). The power of inversion. Irony, from utterance to discourse, in Ruiz Gurillo \& Alvarado Ortega (2013), p. 17-38, Crossref.

Ruiz Gurillo, L. \& Alvarado Ortega, B. (eds) (2013). Irony and Humour. From pragmatics to discourse, John Benjamins, Amsterdam / Philadelphia, Crossref.

Sperber, D. (1996). Explaining Culture. A Naturalistic Approach, Blackwell, Oxford.

Sperber, D. \& Claidière, N. (2008). Defining and explaining culture (comments on Richerson and Boyd, Not by genes alone), in "Biology \& Philosophy", 23 (2), p. 283-292, Crossref.

Sperber, D. \& Wilson, D. (1978). Les ironies comme mentions, in "Poétique", 36, p. 399-412.

Sperber, D. \& Wilson, D. (1981). Irony and the use-mention distinction, in Cole, P. (ed.), Radical Pragmatics, Academic Press, New York, p. 295-318.

Sperber, D. \& Wilson, D. (1995 [1986]). Relevance. Communication and Cognition, Wiley-Blackwell, Oxford, $2^{\text {nd }}$ ed.

Torres Sánchez, M. A. (1999). Estudio pragmático del humor verbal, University of Cádiz, Cádiz.

Wilson, D. (1999). Metarepresentation in linguistic communication, in "UCL Working Papers in Linguistics", 11, p. 127-162.

Wilson, D. (2006). The pragmatics of verbal irony: Echo or pretence?, in "Lingua", 116 (10), p. 1722-1743, Crossref.

Wilson, D. (2009). Irony and metarepresentation, in "UCL Working Papers in Linguistics", 21, p. 183-226.

Wilson, D. (2011). Relevance theory and the interpretation of literary works, in "UCL Working Papers in Linguistics", 23, p. 6980.

Wilson, D. (2013). Irony comprehension: A developmental perspective, in "Journal of Pragmatics", 59, part A, p. 40-56, Crossref.

Wilson D. \& Sperber, D. (2004). Relevance Theory, in Horn, L. R. \& Ward, G. (eds), The Handbook of Pragmatics, Blackwell, Oxford, p. 607-632.

Yus, F. (1995-1996). La teoria de la relevancia y la estrategia humoristica de la incongruencia-resolución, in "Pragmalingüística", 3-4, p. 497-508.

Yus, F. (1997-1998). Irony: context accessibility and processing effort, in "Pragmalingüística", 5-6, p. 391-410, Crossref.

Yus, F. (1999a). Misunderstandings and explicit/ implicit communication, in "Pragmatics", 9 (4), p. 487-517, Crossref. 
Yus, F. (1999b). Towards a pragmatic taxonomy of misunderstandings, in “Revista Canaria de Estudios Ingleses”, 38, p. $217-239$. Yus, F. (2000). On reaching the intended ironic interpretation, in “International Journal of Communication”, 10 (1-2), p. 27-78. Yus, F. (2000-2001). Literal/ non-literal and the processing of verbal irony, in "Pragmalingüística”, 8-9, p. 349-374, Crossref. Yus, F. (2003). Humor and the search for relevance, in "Journal of Pragmatics”, 35 (9), p. 1295-1331, Crossref.

Yus, F. (2004). Pragmatics of humorous strategies in El club de la comedia, in Márquez-Reiter, R. \& Placencia, M.E. (eds), Current Trends in the Pragmatics of Spanish, Benjamins, Amsterdam, p. 320-344, Crossref.

Yus, F. (2009). Saturación contextual en la comprensión de la ironia, in Ruiz Gurillo, L. \& Padilla García, X. (eds), Dime cómo ironizas y te diré quién eres. Una aproximación pragmática a la ironia, Peter Lang, Frankfurt, p. 309-331.

Yus, F. (2012). Relevance Theory and contextual sources-centred analysis of irony. Current research and compatibility, paper delivered at EPICS V, Pablo de Olavide University (Seville, Spain), March.

Yus, F. (2013). An inference-centered analysis of jokes. The intersecting circles model of humorous communication, in Ruiz Gurillo \& Alvarado Ortega (2013), p. 59-82, Crossref.

Yus, F. (2016a). Humour and Relevance, John Benjamins, Amsterdam / Philadelphia, Crossref.

Yus, F. (2016b). Relevance theory and contextual sources-centred analysis of irony. Current research and compatibility, in Padilla Cruz, M. (ed.), Relevance Theory: Recent Developments, Current Challenges and Future Directions, John Benjamins, Amsterdam / Philadelphia, p. 147-171, Crossref.

Yus, F. (2016c). Propositional attitude, affective attitude and irony comprehension, in "Pragmatics \& Cognition", 23 (1), p. $92-$ 116, Crossref.

Yus, F. (2017). Relevance-theoretic treatments of humor, in Attardo, S. (ed.), Routledge Handbook of Language and Humor, Routledge, Abingdon, p. 189-202, Crossref. 